\title{
Targeting PTEN using small molecule inhibitors
}

\author{
${ }^{1}$ Lok Hang Mak and ${ }^{1,2}$ Rudiger Woscholski \\ ${ }^{1}$ Department of Chemistry, Imperial College London, Exhibition Road, London SW7 2AZ, U.K. \\ ${ }^{2}$ Institute of Chemical Biology, Imperial College London, Exhibition Road, London SW7 2AZ, U.K. \\ Corresponding authors:
}

Lok Hang Mak, Imperial Collge London, Department of Chemistry, Exhibition Road, London, SW7 2AZ, UK, lok.mak@imperial.ac.uk, Tel: +44(0)2075945328

Rudiger Woscholski, Imperial Collge London, Department of Chemistry, Exhibition Road, London, SW7 2AZ, UK, r.woscholski@imperial.ac.uk, Tel: +44(0)2075945305

\begin{abstract}
PTEN (phosphatase and tensin homologue deleted on chromosome 10) is well known as a tumour suppressor. It's $\mathrm{PI}(3,4,5) \mathrm{P}_{3}$ lipid phosphatase activity is an important counteracting mechanism in PI3K (phosphoinositide 3-kinase) signalling. Furthermore, PTEN lies upstream of Akt kinase, a key enzyme in insulin signalling regulating glucose uptake and cell growth. Therefore, PTEN has recently gained attention as a valuable drug target for the treatment of diabetes, stroke, cardiac infarct and fertility. This review summarizes the use of small molecules as PTEN inhibitors. Currently available methodologies and techniques for accessing PTEN inhibition in vitro and in cellulo will be discussed.
\end{abstract}

Keywords: PTEN, inhibition, Vanadium compounds, OMFP, VO-OHpic

\section{$1 \quad$ Introduction}

The phosphatidylinositol (PI) 3-phosphatase PTEN has been initially characterised as tumour suppressor gene with a putative tyrosine phosphatase domain [1], but has since then proven to be a dual specificity phosphatase having inositol lipids as substrates [2]. PTEN is dephosphorylating 3phosphorylated inositol lipids, counteracting the action of PI3 kinases by removing the "second messengers" created by the action of growth factors, cytokines and cell survival stimulators [2-4]. Chemical intervention tools, such as wortmannin [5], LY294002 [6] or theophylline [7] facilitated the discovery of new chemical inhibitors, with all chemical intervention tools having a tremendous impact on the elucidation of the role of PI 3-kinases in disease and cancer development $[8,9]$. PTEN was discovered much later than the PI 3-kinases, and the first PTEN inhibitors were developed in due course a decade ago exploiting the dual specificity nature of the PTEN phosphatase.

Bisperoxovanadium compounds were known tyrosine phosphatase inhibitors, which showed a remarkable potency for PTEN in vitro and in vivo [10]. However, these inhibitors are rather promiscuous targeting PTEN in the nanomolar dosage range as well as other phosphatases containing the CX5R active site motif, whereas the 2nd generation PTEN inhibitor VO-OHpic is fairly specific 
for PTEN in vitro and in vivo [11]. These vanadium-based PTEN inhibitors are currently employed in cellular and animal investigations with some recent applications being listed in Table 1 .

Given its role as a tumour suppressor it is not surprising that PTEN has been implicated as a biomarker for certain cancers, in particular those affecting the uterus, brain, skin and prostate [12-14]. A complete loss of this enzyme triggers PTEN induced cellular senescence (PICS) via a p53 dependent mechanism [15]. In contrast, a partial loss of PTEN such as in PTEN (+/-) cells will not be sufficient to counteract the elevated PI 3-kinase activities in cancers, but at the same time will fail to trigger PICS. The consequence of this is a loss of tumour suppression in cancer cells carrying only one active copy of PTEN (haploid insufficiency). Thus, PTEN inhibitors might therefore not just be important research tools, but may be the first steps towards a future drug discovery programmes for PICS based cancer therapy.

Taken these observations together it is important to understand how the properties of the PTEN inhibitors will affect the determination of PTEN activities in vitro and in vivo. Here, we summarise the current experimental knowledge about the application of PTEN inhibitors, with particular reference to the choice of substrates and the assay conditions.

\section{Measuring PTEN inhibition in vitro}

\subsection{Choices of substrates}

PTEN is a dual-specific phosphatase belonging to the family of protein tyrosine phosphatases (PTP) due to its signature active site motif CX5R, yet several studies have indicated that PTEN has rather poor enzymatic activity towards synthetic peptides and para-Nitrophenylphosphate (pNPP ). It has therefore been proposed, that PTEN is unlikely to be a classical PTP utilising protein substrates in vivo, with the most likely physiological substrate being $\mathrm{PI}(3,4,5) \mathrm{P}_{3}$, a key player in cell growth signalling [16]. A comparison of kinetic parameters of PTEN towards various substrates (Table 1) reveals a $\sim 3$-fold lower $\mathrm{K}_{\mathrm{M}}$ for $\mathrm{PI}(3,4,5) \mathrm{P}_{3}$ and a 10 fold higher Vmax than its soluble headgroup $\mathrm{IP}_{4}$ and $\sim 800$-fold lower Vmax than $\mathrm{pNPP}$, demonstrating that in vitro $\mathrm{PI}(3,4,5) \mathrm{P}_{3}$ is as well the preferred substrate. Another substrate that has been tested is 3-O-Methylfluorescein phosphate (OMFP), an artificial substrate also suitable for phosphatases of the PTP family. The use of OMFP over pNPP has two advantages. Firstly, OMFP can be used both as a fluorogenic or colorimetric substrate, whereby the fluorescence detection is preferred due to higher sensitivity. Secondly, PTEN shows a $\sim 100$ times higher affinity towards OMFP $\left(\mathrm{K}_{\mathrm{M}}\right.$ of $\left.216 \pm 14 \mu \mathrm{M}\right)$ as compared to pNPP $\left(\mathrm{K}_{\mathrm{M}}\right.$ of $\left.25.6 \mathrm{mM}\right)$.

While it is apparent that the substrate of choice for PTEN inhibition studies is $\mathrm{PI}(3,4,5) \mathrm{P}_{3}, \mathrm{OMFP}$ is a reliable substrate alternative for PTEN inhibition studies [37], which has the advantage of continuously monitoring the progress of the enzyme activity. In contrast, the $\mathrm{PI}(3,4,5)_{3}$ assay is an endpoint determination of the phosphate released by the enzymatic activity of PTEN. OMFP is therefore suitable for high-throughput screening of compound libraries, which can be complemented with assays employing the physiological substrate $\mathrm{PI}(3,4,5) \mathrm{P}_{3}$ in order to validate any hits. 
As mentioned above, $\operatorname{PI}(3,4,5)_{3}$ is the substrate of choice when determining PTEN activities, but it is also more cumbersome than assaying PTEN using OMFP. To measure PTEN activity using PI $(3,4,5)_{3}$ as a substrate the release of inorganic phosphate will be determined by adding molybdate under strong acidic conditions (section 4.1), which also denature the enzyme and thus terminate the reaction (endpoint assay). The resulting complex of phosphomolybdate can react with malachite green creating a corresponding colour change. Lipid substrates like PI $(3,4,5)_{3}$ or other phosphoinositide can be presented as mixed lipid-detergent micelles, with Octyl $\beta$-D-glucopyranoside (OG) being a good choice due to its low trace amounts of phosphate. The latter is an important consideration, as some detergents will create considerable backgrounds that impact on the overall suitability of the assay.

As previously mentioned (see Table 1), several vanadium based compounds are currently used to inhibit PTEN. The two main groups of PTEN inhibitors consist of bisperoxovanadium (V) compounds with various ligands and VO-OHpic with vanadium in the oxidation state of IV which were tested for their selectively. Kinetic analysis in the presence of bpVpic (vanadium V) and VOOHpic were studied using the enzymes PTEN, PTP1B and SopB, which contain the signature motif CX5R characteristic of the PTP family. Although sharing the same active site motif, each enzyme has a unique substrate preference. PTP1B for example, described in the literature as valuable type 2 diabetes target, is a classical PTP acting on proteinaceous substrates [17]. SopB on the other hand, is a bacterial virulence factor with phosphoinositide phosphatase activity which has the capability to hydrolyse all seven natural occurring phosphoinositides $[18,19]$. We performed a kinetic study of these three enzymes in the presence of bpVpic and VO-OHpic to obtain IC50 values using OMFP as substrate. As shown in table 3, compound bpVpic inhibits all three tested enzyme with similar potency with IC50s in the range of 30 to $40 \mathrm{nM}$. In contrast VO-OHpic, shows specificity towards PTEN with an IC50 of $39.6 \pm 2.1 \mathrm{nM}$. The IC50s for PTP1B is $\sim 20$-fold higher and $\sim 13$-fold higher for SopB as compared to PTEN. Taken all this observations together, VO-OHpic seems to be the choice of compounds, if PTEN is to be selectively inhibited, which is in agreement with our earlier investigation [11].

EDTA has been routinely use in the literature to assay PTP activity as well as probing for reversibility of potent inhibitors [20]. Interestingly, if EDTA is included in the assay solution, the inhibition of all three tested enzymes by VO-OHpic is fully abolished. EDTA is a known for its strong metal chelating characteristics. It is therefore likely, that EDTA chelates the vanadium within the VO-OHpic complex thus destroying the VO-OHpic complex. In contrast, the bisperoxovanadium bpVpic seems to withstand the presence of EDTA as similar IC50s were obtained with and without EDTA. Since EDTA is routinely used in inhibitor screening for PTPs, it is of importance to validate the effect of EDTA especially if metal-based compounds are screened, which can affect compound stability and activity.

\section{$3 \quad$ Measuring PTEN inhibition in cellulo}

One way to measure PTEN inhibition in cellulo is to monitor the status of downstream effectors of PTEN-dependent signalling, such as the protein kinase Akt, also known as protein kinase B. Akt kinase plays a key role in multiple cellular processes such as glucose metabolism, cell proliferation, apoptosis, transcription and cell migration [21]. The activity of Akt is regulated by two 
phosphorylation sites, namely serine 473 (Ser473) and threonine 308 (Thr308). Upon activation of PI3 kinase, the phosphoinositide-dependent kinase 1 (PDK1) is translocated to the plasma membrane by binding to $\mathrm{PI}(3,4,5) \mathrm{P}_{3}$. PDK1, a serine-threonine kinase, phosphorylates Akt in a $\mathrm{PI}(3,4,5) \mathrm{P}_{3}$ dependent manner at $\mathrm{Thr} 308$. To become fully activated, Akt requires phosphorylation at serine 473 (Ser473), which is phosphorylated by mammalian target of rapamycin complex 2

(mTORC2) [22]. Through counteracting PI3 kinase, the Akt signalling is terminated by the action of PTEN in dephosphorylating $\mathrm{PI}(3,4,5) \mathrm{P}_{3}$. Although, the inositol-5-phosphatase SHIP1 and SHIP2 are capable of dephosphorylating $\mathrm{PI}(3,4,5) \mathrm{P}_{3}$ at the $\mathrm{D} 5$ position, it has been shown that PTEN is mainly responsible for attenuating PI3 kinase signalling, making Akt phosphorylation a bona fide readout for PTEN activity in cellulo [23] .

As can be seen in Figure 1 the phosphorylation levels of Akt at Thr308 as well as Ser473 increases in the presence of PTEN inhibitor VO-OHpic. An activation at a concentration of $50 \mathrm{nM}$ can already be detected which is in good agreement with the known in vitro VO-OHpic potency [11,24], demonstrating the good cell permeability of this inhibitor. The fact that $50 \mathrm{nM}$ of VO-OHpic is sufficient to exert cellular effects also means that the chance of hitting other phosphatases can be reduced to a minimum as the determined IC 50s for other Cx5R phosphatases is at least 10-fold higher as shown in table 3 .

In order to detect PTEN dependent activation of Akt, it is crucial to starve cells to bring PI3 kinase activity to a very low basal level, without completely blocking it. PI3 kinase generates the substrate for PTEN and thus needs to be active, but too much PI3 kinase activity would overshadow the effect PTEN inhibition might have on the overall dynamic balance between $\operatorname{PI}(4,5) \mathrm{P}_{2}$ and $\mathrm{PI}(3,4,5) \mathrm{P}_{3}$. Therefore, starved cells are stimulated with a low dose of growth factors in order to activate sufficient amounts of PI3 kinase, which in turn will generate small $\mathrm{PI}(3,4,5) \mathrm{P}_{3}$ levels that can be removed by the PTEN, leaving enough $\mathrm{PI}(3,4,5) \mathrm{P}_{3}$ to just activate Akt kinase above the baseline. The dose of growth factor (e.g. insulin) needs to be determined prior to experiments on PTEN inhibition in the cellular environment. It is important to use a concentration in the low linear phase of a dose-dependent activation of Akt kinase, since this will provide the necessary dynamic range to detect changes in Akt activation. As shown in figure 1, low insulin will generate a low basal level of Akt activation that can be increased by adding the PTEN inhibitor. Whereas high level of insulin (see Figure 2) will result in such high cellular levels of $\mathrm{PI}(3,4,5) \mathrm{P}_{3}$ that will not be significantly affected by inhibiting PTEN. The activation of Akt due to high insulin doses is almost saturated, and thus are not any more limited by PTEN's counteraction against the insulin dependent activation of PI 3kinase. It is therefore of utmost importance to determine the concentration of growth factor that generates an Akt kinase activation well below the saturation phase.

The activity of PTEN in vivo can also be measured by quantifying cellular $\mathrm{PI}(3,4,5) \mathrm{P}_{3}$ levels upon treatment with PTEN inhibitors. Lipids can be extracted and then analysed using lipid-binding protein domains to detect phosphoinositides [25]. The PLC- $\delta 1 \mathrm{PH}$ domain for example, has been extensively used to detect $\mathrm{PI}(4,5) \mathrm{P}_{2}$ in fluorescence microscopy techniques either on live or post-fixation cells.

With respect to $\mathrm{PI}(3,4,5) \mathrm{P}_{3}$ binding domains the Akt and GRP1 $\mathrm{PH}$ domains are employed the most [26]. The GRP1 PH domain is known to be highly specific for $\mathrm{PI}(3,4,5) \mathrm{P}_{3}$ whereas the Akt $\mathrm{PH}$ 
domain is known to bind $\mathrm{PI}(3,4) \mathrm{P}_{2}$ with similar affinity. The GRPH1 PH domain has been used as a probe to visualize PtdIns $(3,4,5) \mathrm{P}_{3}$ in cells by live imaging as well as in electron microscopy [27].

The amount of cellular $\mathrm{PI}(3,4,5) \mathrm{P}_{3}$ levels can be detected using the protein-lipid overlay assay once the lipid has been extracted from the cells. Figure 3 shows the result of a protein-lipid overlay assay, after treating NIH3T3 with indicated concentrations of VO-OHpic. As shown the amount of $\mathrm{PI}(3,4,5) \mathrm{P}_{3}$ detected upon treatment with increasing concentration of VO-OHpic is in good agreement with the activation level of phospho-Akt (Figure1), making the protein-lipid overlay assay a good alternative readout when accessing PTEN inhibition in a cellular environment. There are possibilities to use microscopy methods for testing PTEN inhibitors, which would add spatial resolution to the general inhibitory data [28]. While the general precautions concerning the basal activation levels of Akt phosphorylation (see above) will apply also to any cellular imaging technique, the choice of effector being monitored as well as the cell type will have a substantial influence on the optimal conditions for monitoring PTEN dependent effects on cellular function.

The results shown here summarize some recent methodologies and techniques in accessing PTEN inhibition by small molecule in vitro and in vivo. Two different PTEN activity assays are described to measure PTEN activity/inhibition in vitro using purified enzyme. Each of the two PTEN activity assay described here has their advantage. While the PTEN assay with OMFP substrate offers a simple, on-line recording assay with high-throughput capability, the malachite green assay employs the physiological substrate $\mathrm{PI}(3,4,5) \mathrm{P}_{3}$. In a cellular environment, the inhibitory effect of small molecules on PTEN can be measured by detecting downstream effectors of the PTEN signalling, namely by detecting the activation of the $\mathrm{PI}(3,4,5) \mathrm{P}_{3}$-dependent protein kinase Akt. Alternatively, the detection of changes in cellular $\mathrm{PI}(3,4,5) \mathrm{P}_{3}$ levels upon PTEN inhibition by the protein-lipid overlay assay can also be employed to measure PTEN inhibition.

\section{Experimental procedures for measure PTEN inhibition in vitro and in cellulo}

\section{Methods}

\section{Materials:}

- Recombinant active PTEN phosphatase (Expressed as GST-fusion in E.coli)

- $\quad$ Tris-HCl (\#93363, Sigma-Aldrich)

- DL-Dithiothreitol (DTT) (\#43815, Sigma-Aldrich)

- $\quad \mathrm{PI}(3,4,5) \mathrm{P}_{3}$, diC16-Na (\#208, CellSignals)

- $\mathrm{I}(1,3,4,5) \mathrm{P}_{4},(\# 501$, CellSignals $)$

- 4-nitrophenyl phosphate (pNPP), (\#71768, Sigma-Aldrich)

- 3-O-Methylfluorescein phosphate (OMFP), (M2629, Sigma Aldrich)

- 3-O-Methylfluorescein (OMF), (BIM0143, Apollo Scientific) 
- Octyl $\beta$-D-glucopyranoside (OG), (\#494459, Calbiochem)

- Malachite Green oxalate salt, (\#M6880, Sigma-Aldrich)

- Ammonium molybdate tetrahydrate, (\#09878, Sigma-Aldrich)

- Bismuth(III) citrate, (\#480746, Sigma-Aldrich)

- Hydrochloric acid 37\%, (\#320331, Sigma-Aldrich)

\subsection{Inhibition assay of PTEN using $P I(3,4,5) P_{3}$ as substrate}

1. Malachite green dye preparation: A 2x concentrated malachite green reagent is prepared by dissolving $5 \mathrm{mM}$ malachite green, $17 \mathrm{mM}$ ammonium heptamolybdate, $77 \mathrm{mM}$ bismuth citrate and $1.7 \mathrm{M} \mathrm{HCl}$ in distilled water. The mixture is stirred overnight in the dark and filtered next day. A calibration curve for inorganic phosphate can be obtained using $\mathrm{KH}_{2} \mathrm{PO}_{4}$.

2. $\mathrm{PI}(3,4,5) \mathrm{P}_{3}$ substrate preparation: To prepare a $300 \mu \mathrm{M}(10 \mathrm{x}$ stock $)$ substrate solution, $\mathrm{PIP} 3$ is dissolved in MilliQ grade distilled water with $1 \%(\mathrm{w} / \mathrm{v})$ Octyl $\beta$-D-glucopyranoside. The solution is mixed briefly and sonicated in a bench top bath sonicator for $10 \mathrm{~min}$. After sonication, the substrate solution is kept on ice until use.

3. VO-OHpic inhibitor preparation. For inhibition studies, VO-OHpic is prepared as a 10x stock solution in $10 \%$ DMSO at concentration ranging between $10 \mathrm{nM}$ to $10 \mu \mathrm{M}$.

4. Enzyme activity of PTEN is measured in $100 \mathrm{mM}$ Tris (pH 7.4) containing $0.5 \mathrm{mM}$ DTT. For a $100 \mu \mathrm{L}$ reaction, $80 \mu \mathrm{L}$ of the PTEN mixture containing $100 \mathrm{mM}$ Tris and $0.5 \mathrm{mM}$ DTT is pre-incubated with $10 \mu \mathrm{L}$ of the $10 \mathrm{x}$ stock solution of VO-OHpic into a 96-well plate. For the control reaction. Pre-incubate at room temperature for $10 \mathrm{~min}$. After $10 \mathrm{~min}$, add $10 \mu \mathrm{L}$ of the 10x substrate stock solution to the control and reaction wells. Incubate the reaction for $20 \mathrm{~min}$ at $37^{\circ} \mathrm{C}$.

5. After reaction time, stop the reaction by adding $100 \mu \mathrm{L}$ of malachite green dye to the reaction and the control well. Add $80 \mu \mathrm{L}$ of PTEN mixture to the control well. Let the dye to develop for $10 \mathrm{~min}$ at room temperature. Read the absorbance at $625 \mathrm{~nm}$.

6. Calculate the PTEN activity by subtracting the relevant blanks. 
7. Use standard curves to transform activities from OD units to molar turnover.

\subsection{PTEN inhibition assay with OMFP as substrate}

1. OMFP substrate preparation: The cyclohexylammonium salt of 3-O-Methylfluorescein phosphate (OMFP) is dissolved in DMSO to a concentration of $20 \mathrm{mM}$. Sonication might be required to accelerate the process. DMSO stock solutions of OMFP can be stored at $-20^{\circ} \mathrm{C}$ in the dark. For inhibition assays, a 10x stock solution is prepared by diluting OMFP to a concentration of $2 \mathrm{mM}$ containing $10 \%$ DMSO.

2. The enzyme activity of PTEN is measured in $100 \mathrm{mM}$ Tris (pH 7.4) containing $0.5 \mathrm{mM}$ DTT. For a $100 \mu \mathrm{L}$ reaction, $80 \mu \mathrm{L}$ of the PTEN mixture containing $100 \mathrm{mM}$ Tris and $0.5 \mathrm{mM}$ DTT is pre-incubated at room temperature with $10 \mu \mathrm{L}$ of the 10x stock solution of PTEN inhibitor using a 96-well plate. After $10 \mathrm{~min}$, reactions were initialised by adding $10 \mu \mathrm{L}$ of the $10 \mathrm{x}$ substrate stock solution (OMFP) to the PTEN-buffer mixture. The conversion of OMFP to OMF by PTEN will cause a corresponding change in fluorescence units (FU) in the 96-well microtiter plate (excitation at $485 \mathrm{~nm}$ and emission at $525 \mathrm{~nm}$ ), which can be used to monitor PTEN activity continuously.

\subsection{Cellular PTEN inhibition assay}

Materials

1. Cell line: NIH 3T3 mouse fibroblasts (or other PTEN expressing cell lines)

2. Dulbecco's Modified Eagle's Medium, high glucose (DMEM) (D5671, Sigma-Aldrich) supplemented with $10 \%$ newborn calf serum (ATCC)

3. Dulbecco's Modified Eagle's Medium, low glucose (DMEM) (D6046, Sigma-Aldrich)

4. Phosphate buffer saline (PBS) (Gibco, Life Technologies)

5. Trypsin-EDTA solution (T4174, Sigma-Aldrich) 
6. Insulin (I6634, Sigma-Aldrich). Prepare a $1 \mathrm{mg} / \mathrm{mL}$ solution in $0.02 \mathrm{M} \mathrm{HCl}$, filter-sterilised and store in aliquots at $-20^{\circ} \mathrm{C}$.

7. PTEN inhibitor VO-OHpic at final concentration ranging between $50 \mathrm{nM}$ and $1 \mu \mathrm{M}$.

8. 1 x SDS sample buffer: $62.5 \mathrm{mM}$ Tris- $\mathrm{HCl} \mathrm{pH}$ 6.8, $2.5 \%$ SDS, $0.002 \%$ Bromophenol Blue, $5 \% \beta$-mercaptoethanol, $10 \%$ glycerol

9. Phospho-Akt (Ser473) antibody (Cell Signaling)

10. Phospho-Akt (Thr308) antibody (Cell Signaling)

11. Akt antibody (Cell Signaling)

12. Tris-buffered saline with $0.1 \%$ Tween 20 (TBST): $20 \mathrm{mM}$ Tris, $\mathrm{pH} 7.4,150 \mathrm{mM} \mathrm{NaCl}, 0.1 \%$ Tween $20(\mathrm{v} / \mathrm{v})$.

Method

1. NIH 3 T3 mouse fibroblast are grown in DMEM, high glucose with $10 \%$ newborn calf serum and passaged when required (around $80-90 \%$ confluency) using trypsin/EDTA to maintain cultures. For PTEN inhibition experiment passage cells 1 in 10 into $60 \mathrm{~mm}$ dishes. Grow cells until $70-80 \%$ confluency.

2. Wash cells twice with PBS and starved in low glucose DMEM without serum for 16 hours.

3. After starvation, wash dishes with PBS and add fresh starvation medium.

4. Add PTEN inhibitor and solvent control to dishes and incubate in a $\mathrm{CO}_{2}$ incubator for $30 \mathrm{~min}$.

5. Add insulin to a final concentration of $0.02 \mu \mathrm{g} / \mathrm{mL}$ and incubate for $10 \mathrm{~min}$.

6. Remove media and wash cells twice with ice-cold PBS.

7. Add $300 \mu \mathrm{L}$ of $1 \mathrm{x}$ SDS lysis buffer to each dish and scrape cells of into a $1.5 \mathrm{~mL}$ centrifuge tube.

8. Boil sample $94^{\circ} \mathrm{C}$ for $5 \mathrm{~min}$ and cool on ice.

9. Run SDS gel electrophoresis and transfer the protein onto a nitrocellulose membrane according to manufacturer's instructions. 
10. Block the membrane using a 5\% milk powder solution in TBST for 1 hour at room temperature.

11. Wash the membrane twice with TBST for 5 min each.

12. Incubate the membrane with a 1:1000 dilution of phospho-Akt antibody or pan-Akt antibody in TBST containing $5 \% \mathrm{BSA}$ at $4^{\circ} \mathrm{C}$ for 16 hours.

13. Wash membrane 3 times for 10 min with TBST.

14. Incubate membrane with appropriate secondary antibody according to manufacturer's instructions.

15. Wash as in step 13. Visualise western blot using ECL solution according to manufacture specification.

\subsection{Protein-lipid overlay assay for detecting cellular PI(3,4,5)P3 levels upon PTEN inhibition}

Materials

1. Cell line: NIH $3 \mathrm{~T} 3$ mouse fibroblasts (or other PTEN expressing cell lines)

2. Dulbecco's Modified Eagle's Medium, high glucose (DMEM) (D5671, Sigma-Aldrich) supplemented with $10 \%$ newborn calf serum (ATCC)

3. Dulbecco's Modified Eagle's Medium, low glucose (DMEM) (D6046, Sigma-Aldrich)

4. Phosphate buffer saline (PBS) (Gibco, Life Technologies)

5. Trypsin-EDTA solution (T4174, Sigma-Aldrich)

6. Insulin (I6634, Sigma-Aldrich). Prepare a $1 \mathrm{mg} / \mathrm{mL}$ solution in $0.02 \mathrm{M} \mathrm{HCl}$, filter-sterilised and store in aliquots at $-20^{\circ} \mathrm{C}$.

7. PTEN inhibitor VO-OHpic

8. Recombinant GRP1 PH domain (Expressed as GST-fusion protein in our laboratory)

9. Anti-GST HRP conjugated antibody

10. ECL reagent or similar 
11. Hybond-C extra nitrocellulose membrane (GE Healthcare)

12. Chloroform

13. Methanol

Methods

1. NIH 3 T3 mouse fibroblast are grown in DMEM, high glucose with 10\% newborn calf serum and passaged when required (around $80-90 \%$ confluency) using trypsin/EDTA to maintain cultures. For PTEN inhibition experiment passage cells 1 in 10 into $100 \mathrm{~mm}$ dishes. Grow cells until 70-80\% confluency.

2. Wash cells twice with PBS and starved in low glucose DMEM without serum for 16 hours.

3. After starvation, wash dishes with PBS and add fresh starvation medium.

4. Add PTEN inhibitor and solvent control to dishes and incubate

5. Add insulin to a final concentration of $0.05 \mu \mathrm{g} / \mathrm{mL}$ and incubate in a $\mathrm{CO}_{2}$ incubator for 30 $\min$.

6. Remove media and wash cells twice with ice-cold PBS.

7. Add $5 \mathrm{~mL}$ of $0.5 \mathrm{M}$ ice-cold TCA to the dish and scrape cells of into a $15 \mathrm{~mL}$ centrifuge tube.

8. Centrifuge sample at $1500 \mathrm{rpm}$ for $10 \mathrm{~min}$ and discard the supernatant.

9. Wash the pellet with $2 \mathrm{~mL}$ of $5 \% \mathrm{TCA} / 1 \mathrm{mM}$ EDTA. Centrifuge at $1500 \mathrm{RPM}$ for $10 \mathrm{~min}$ and discard the supernatant.

10. To extract PIP3 add $750 \mu \mathrm{L}$ of Methanol:Chloroform:H2O (80:40:1) and incubate at room temperature for $15 \mathrm{~min}$. Vortex in between.

11. Centrifuge for $10 \mathrm{~min}$ at $1500 \mathrm{rpm}$ and transfer supernatant in a $1.5 \mathrm{~mL}$ centrifuge tube.

12. Add $250 \mu \mathrm{L}$ of Chloroform and 450 of $0.1 \mathrm{M} \mathrm{HCl}$ to induce phase split. Incubate sample for $10 \mathrm{~min}$ at room temperature and vortex every $2 \mathrm{~min}$. Centrifuge at $1500 \mathrm{rpm}$ for $10 \mathrm{~min}$ and collect lower phase into a new centrifuge tube. Dry down lipids and re-suspend into $20 \mu \mathrm{L}$ of a solution of methanol:chloroform:water (2:1:0.8) and vortex briefly. 
13. Spot a total of $5 \mu \mathrm{L}$ of lipid extracts for every studied condition onto a Hybond $\mathrm{C}$ nitrocellulose membrane. Spot $1 \mu \mathrm{L}$ at a time, let the membrane dry and add another $1 \mu \mathrm{L}$ up to a total of $5 \mu \mathrm{L}$.

14. Let the membrane dry at room temperature for 1 hour.

15. Block the membrane with $2 \mathrm{mg} / \mathrm{mL}$ of fatty acid free BSA in TBST for 1 hour at room temperature.

16. Incubate the membrane with $10-50 \mathrm{nM}$ of GRPH1 PH domain for 16 hours at $4^{\circ} \mathrm{C}$ in blocking buffer.

17. Wash the membrane 5 times $10 \mathrm{~min}$ with TBST.

18. Incubate the membrane with a 1:5000 dilution of anti-GST-HRP conjugated antibody for 1 hour at room temperature in blocking buffer.

19. Wash as in 17.

20. Visualise the membrane using ECL reagent and chemiluminescence reader.

\section{Figure captions}

Figure 1 NIH 3T3 cells were starved overnight, incubated with indicated concentration of VOOHpic for $30 \mathrm{~min}$, followed by insulin stimulation as indicated. Cells were collected and analysed by western blotting using phospho-Akt (Thr308 and Ser473) and total Akt antibodies. The blot in Figure 1 (top panel) is representative of two independent repeats. The resulting blot intensities were quantified using ImageJ where high insulin stimulation $(10 \mu \mathrm{g} / \mathrm{mL})$ was set to $100 \%$ (bottom panel). Error bars shown are the standard error from the two independent experiments.

Figure 2 NIH 3T3 cells were starved overnight, incubated with indicated concentration of VOOHpic for $30 \mathrm{~min}$, followed by insulin stimulation as indicated. Cells were collected and analysed by western blotting using phospho-Akt (Thr308 and Ser473) and total Akt antibodies. The blot in Figure 1A was quantified using ImageJ (http://imagej.nih.gov/ij/) where high insulin stimulation $(10 \mu \mathrm{g} / \mathrm{mL})$ was set to $100 \%$. Blot shown is representative of two independent experiment. 
Figure 3 Protein-lipid Overlay assay to detect $\mathrm{PI}(3,4,5) \mathrm{P}_{3}$ from VO-OHpic treated NIH3T3 cells. NIH 3T3 cells were starved for 16 hours and then treated with VO-OHpic at concentration as indicated. Cells were stimulated with $0.05 \mu \mathrm{g} / \mathrm{mL}$ insulin for $30 \mathrm{~min}$. Lipids were extracted and detected with GST-tagged GRP1 domain. Blot shown is representative of three independent experiment.

\section{References}

1. Li, J., et al., PTEN, a putative protein tyrosine phosphatase gene mutated in human brain, breast, and prostate cancer. Science, 1997. 275(5308): p. 1943-7.

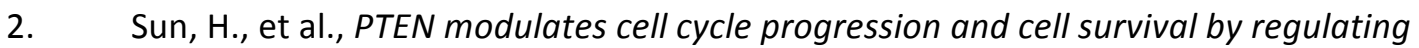
phosphatidylinositol 3,4,5,-trisphosphate and Akt/protein kinase B signaling pathway. Proc Natl Acad Sci U S A, 1999. 96(11): p. 6199-204.

3. Cantley, L.C. and B.G. Neel, New insights into tumor suppression: PTEN suppresses tumor formation by restraining the phosphoinositide 3-kinase/AKT pathway. Proc Natl Acad Sci U S A, 1999. 96(8): p. 4240-5.

4. Di Cristofano, A. and P.P. Pandolfi, The multiple roles of PTEN in tumor suppression. Cell, 2000. 100(4): p. 387-90.

5. Arcaro, A. and M.P. Wymann, Wortmannin is a potent phosphatidylinositol 3-kinase inhibitor: the role of phosphatidylinositol 3,4,5-trisphosphate in neutrophil responses. Biochem J, 1993. 296 ( Pt 2): p. 297-301.

6. Vlahos, C.J., et al., A specific inhibitor of phosphatidylinositol 3-kinase, 2-(4-morpholinyl)-8phenyl-4H-1-benzopyran-4-one (LY294002). J Biol Chem, 1994. 269(7): p. 5241-8.

7. Petritsch, C., et al., Activation of p70 56 kinase and erk-encoded mitogen-activated protein kinases is resistant to high cyclic nucleotide levels in Swiss 3 T3 fibroblasts. J Biol Chem, 1995. 270(44): p. 26619-25.

8. Zhang, J., P.L. Yang, and N.S. Gray, Targeting cancer with small molecule kinase inhibitors. Nat Rev Cancer, 2009. 9(1): p. 28-39.

9. Workman, P., Inhibiting the phosphoinositide 3-kinase pathway for cancer treatment. Biochem Soc Trans, 2004. 32(Pt 2): p. 393-6.

10. Schmid, A.C., et al., Bisperoxovanadium compounds are potent PTEN inhibitors. FEBS Lett, 2004. 566(1-3): p. 35-8.

11. Rosivatz, E., et al., A small molecule inhibitor for phosphatase and tensin homologue deleted on chromosome 10 (PTEN). ACS Chem Biol, 2006. 1(12): p. 780-90.

12. Fujita, T., et al., PTEN activity could be a predictive marker of trastuzumab efficacy in the treatment of ErbB2-overexpressing breast cancer. Br J Cancer, 2006. 94(2): p. 247-52.

13. Koksal, I.T., et al., The assessment of PTEN tumor suppressor gene in combination with Gleason scoring and serum PSA to evaluate progression of prostate carcinoma. Urol Oncol, 2004. 22(4): p. 307-12.

14. Lacey, J.V., Jr., et al., PTEN expression in endometrial biopsies as a marker of progression to endometrial carcinoma. Cancer Res, 2008. 68(14): p. 6014-20.

15. Alimonti, A., et al., A novel type of cellular senescence that can be enhanced in mouse models and human tumor xenografts to suppress prostate tumorigenesis. J Clin Invest, 2010. 120(3): p. 681-93. 
16. Maehama, T., G.S. Taylor, and J.E. Dixon, PTEN and myotubularin: novel phosphoinositide phosphatases. Annu Rev Biochem, 2001. 70: p. 247-79.

17. Johnson, T.O., J. Ermolieff, and M.R. Jirousek, Protein tyrosine phosphatase 1B inhibitors for diabetes. Nat Rev Drug Discov, 2002. 1(9): p. 696-709.

18. Norris, F.A., et al., SopB, a protein required for virulence of Salmonella dublin, is an inositol phosphate phosphatase. Proc Natl Acad Sci U S A, 1998. 95(24): p. 14057-9.

19. Mak, L.H., et al., A small molecule mimicking a phosphatidylinositol (4,5)-bisphosphate binding pleckstrin homology domain. ACS Chem Biol, 2011. 6(12): p. 1382-90.

20. Huyer, G., et al., Mechanism of inhibition of protein-tyrosine phosphatases by vanadate and pervanadate. J Biol Chem, 1997. 272(2): p. 843-51.

21. Stambolic, V., et al., Negative regulation of PKB/Akt-dependent cell survival by the tumor suppressor PTEN. Cell, 1998. 95(1): p. 29-39.

22. Manning, B.D. and L.C. Cantley, AKT/PKB signaling: navigating downstream. Cell, 2007. 129(7): p. 1261-74.

23. Gunn, R.M. and H.C. Hailes, Insights into the PI3-K-PKB-mTOR signalling pathway from small molecules. J Chem Biol, 2008. 1(1-4): p. 49-62.

24. Mak, L.H., R. Vilar, and R. Woscholski, Characterisation of the PTEN inhibitor VO-OHpic. J Chem Biol, 2010. 3(4): p. 157-63.

25. Dowler, S., G. Kular, and D.R. Alessi, Protein lipid overlay assay. Sci STKE, 2002. 2002(129): p. pl6.

26. Weiner, O.D., Rac activation: P-Rex1 - a convergence point for PIP(3) and Gbetagamma? Curr Biol, 2002. 12(12): p. R429-31.

27. Gray, A., J. Van Der Kaay, and C.P. Downes, The pleckstrin homology domains of protein kinase $B$ and GRP1 (general receptor for phosphoinositides-1) are sensitive and selective probes for the cellular detection of phosphatidylinositol 3,4-bisphosphate and/or phosphatidylinositol 3,4,5-trisphosphate in vivo. Biochem J, 1999. 344 Pt 3: p. 929-36.

28. Rosivatz, E. and R. Woscholski, Measurement of PTEN activity in vivo by imaging phosphorylated Akt. Methods Mol Biol, 2009. 462: p. 213-22.

29. Lai, J.P., et al., Inhibition of the phosphatase PTEN protects mice against oleic acid-induced acute lung injury. Br J Pharmacol, 2009. 156(1): p. 189-200.

30. Liu, S., et al., The PI3K-Akt pathway inhibits senescence and promotes self-renewal of human skin-derived precursors in vitro. Aging Cell, 2011. 10(4): p. 661-74.

31. Shi, G.D., et al., PTEN deletion prevents ischemic brain injury by activating the mTOR signaling pathway. Biochem Biophys Res Commun, 2011. 404(4): p. 941-5.

32. Sury, M.D., et al., Restoration of Akt activity by the bisperoxovanadium compound bpV(pic) attenuates hippocampal apoptosis in experimental neonatal pneumococcal meningitis. Neurobiology of Disease, 2011. 41(1): p. 201-208.

33. Chen, Z., et al., Effects of PTEN inhibition on regulation of tau phosphorylation in an okadaic acid-induced neurodegeneration model. Int J Dev Neurosci, 2012. 30(6): p. 411-9.

34. Walker, C.L. and X.M. Xu, PTEN inhibitor bisperoxovanadium protects oligodendrocytes and myelin and prevents neuronal atrophy in adult rats following cervical hemicontusive spinal cord injury. Neurosci Lett, 2014. 573: p. 64-8.

35. Adhikari, D., et al., The safe use of a PTEN inhibitor for the activation of dormant mouse primordial follicles and generation of fertilizable eggs. PLoS One, 2012. 7(6): p. e39034.

36. McLaughlin, M., et al., Inhibition of phosphatase and tensin homologue (PTEN) in human ovary in vitro results in increased activation of primordial follicles but compromises development of growing follicles. Mol Hum Reprod, 2014. 20(8): p. 736-44.

37. Silva, S.R., et al., The Effect of PTEN on Serotonin Synthesis and Secretion from the Carcinoid Cell Line BON. Anticancer Research, 2011. 31(4): p. 1153-1160. 
38. Wen, P.J., et al., Phosphatidylinositol(4,5)bisphosphate coordinates actin-mediated mobilization and translocation of secretory vesicles to the plasma membrane of chromaffin cells. Nat Commun, 2011. 2: p. 491.

39. Zu, L., et al., PTEN inhibitors cause a negative inotropic and chronotropic effect in mice. Eur J Pharmacol, 2011. 650(1): p. 298-302.

40. Tzenaki, N., et al., High levels of p110delta PI3K expression in solid tumor cells suppress PTEN activity, generating cellular sensitivity to p110delta inhibitors through PTEN activation. FASEB J, 2012. 26(6): p. 2498-508.

41. Zhu, X., et al., TAT-Protein blockade during ischemia/reperfusion reveals critical role for p85 PI3K-PTEN interaction in cardiomyocyte injury. PLoS One, 2014. 9(4): p. e95622.

Tables:

\begin{tabular}{|c|c|c|c|c|}
\hline Compound & Dose & Cell tissue/Organ & Effect upon PTEN inhibition & Ref \\
\hline bpV(phen) & $0.4 \mu \mathrm{mol} / \mathrm{mouse}$ & C57BL/6 Mice & $\begin{array}{l}\text { Increased lung tissue levels of } \\
\text { phospho-Akt and ERK }\end{array}$ & [29] \\
\hline $\mathrm{bpV}(\mathrm{pic})$ & $5 \mu \mathrm{M}$ & Skin-derived precursors & $\begin{array}{l}\text { Enhancing the PI3K-Akt path- } \\
\text { way through PTEN inhibition } \\
\text { improved self-renewal of human } \\
\text { foreskin }\end{array}$ & {$[30]$} \\
\hline $\mathrm{bpV}(\mathrm{pic})$ & $20 \mu \mathrm{g} / 100 \mathrm{~g}$ & Wistar rats & $\begin{array}{l}\text { Prevents ischemic brain injury by } \\
\text { activating the mTOR signaling } \\
\text { pathway }\end{array}$ & {$[31]$} \\
\hline $\mathrm{bpV}(\mathrm{pic})$ & $2 \mathrm{mg} / 1000 \mathrm{~g}$ & Wistar rats & $\begin{array}{c}\text { Attenuation of hippocampal } \\
\text { apoptosis }\end{array}$ & {$[32]$} \\
\hline $\mathrm{bpV}(\mathrm{pic})$ & $10-90 \mathrm{nM}$ & SH-SY5Y cells & $\begin{array}{l}\text { Reduction of okadaic acid- } \\
\text { induced tau phosphorylation }\end{array}$ & {$[33]$} \\
\hline $\mathrm{bpV}(\mathrm{pic})$ & $200 \mu \mathrm{g} / \mathrm{kg}$ & $\begin{array}{l}\text { Adult female Sprague- } \\
\text { Dawley rats }\end{array}$ & $\begin{array}{c}\text { Injury-induced neuronal soma } \\
\text { atrophy was reversed by PTEN } \\
\text { inhibition }\end{array}$ & {$[34]$} \\
\hline bpV(OHpic) & $1 \mu \mathrm{M}$ & Neonatal mouse ovaries & $\begin{array}{l}\text { Demonstrated the use of PTEN } \\
\text { inhibitor to generate mature } \\
\text { human oocytes for use in novel } \\
\text { IVF techniques }\end{array}$ & {$[35]$} \\
\hline bpV(OHpic) & $1 \mu \mathrm{M}$ & Ovarian cortical tissue & $\begin{array}{c}\text { Affects human ovarian follicle } \\
\text { development by promoting the } \\
\text { initiation of folliclegrowth and } \\
\text { development to the secondary } \\
\text { stage }\end{array}$ & {$[36]$} \\
\hline VO-OHpic & $500 \mathrm{nM}$ & Human xenograft & $\begin{array}{l}\text { Induced senescence and inhibits } \\
\text { tumorigenesis in vivo }\end{array}$ & {$[15]$} \\
\hline VO-OHpic & $500 \mathrm{nM}$ & Carcinoid cell line BON & $\begin{array}{c}\text { Decreased secretion and synthesis } \\
\text { of serotonin }\end{array}$ & [37] \\
\hline VO-OHpic & $100 \mathrm{nM}$ & $\begin{array}{l}\text { Mouse adrenal chromaffin } \\
\text { cells }\end{array}$ & $\begin{array}{l}\text { Abolished the effect of compound } \\
\text { IC } 87114 \text {, a potent inhibitor of } \\
\text { PI3K } \delta \text { in promoting potentiation } \\
\text { of } \mathrm{Ca} 2+ \\
\text {-stimulated catecholamine release }\end{array}$ & {$[38]$} \\
\hline VO-OHpic & $10 \mu \mathrm{g} / \mathrm{kg}$ & Mice & $\begin{array}{l}\text { Induced cardioprotection against } \\
\text { ischemia-reperfusion injury }\end{array}$ & {$[39]$} \\
\hline VO-OHpic & $500 \mathrm{nM}$ & $\begin{array}{l}\text { Breast cancer cells MDA- } \\
\text { MB- } 231\end{array}$ & $\begin{array}{l}\text { Abolished the } \\
\text { effect of PI3 kinase inhibitor } \\
\text { IC87114 on Akt inhibition }\end{array}$ & {$[40]$} \\
\hline VO-OHpic & $0.1-5 \mu \mathrm{M}$ & $\begin{array}{l}\text { Mouse ventricular } \\
\text { cardiomyocytes }\end{array}$ & $\begin{array}{l}\text { Highly protective against cell } \\
\text { death induced by ischemia and } \\
\text { reperfusion }\end{array}$ & {$[41]$} \\
\hline
\end{tabular}


Table 1: Recent applications of vanadium-based PTEN inhibitors in cellulo and in vivo.

\begin{tabular}{|c|c|c|}
\hline Substrate & $\mathrm{K}_{\mathrm{M}}(\mu \mathrm{M})$ & $\begin{array}{c}\text { Vmax } \\
\left(\text { nmoles }^{*} \mathrm{mg}^{-1} \min ^{-1}\right)\end{array}$ \\
\hline $\mathrm{PI}(3,4,5) \mathrm{P}_{3}$ & $30 \pm 4$ & $47.5 \pm 1.8$ \\
\hline $\mathrm{I}(1,3,4,5) \mathrm{P}_{4}$ & $88 \pm 9$ & $9.1 \pm 0.4$ \\
\hline $\mathrm{pNPP}$ & $25600[16]$ & - \\
\hline OMFP & $216 \pm 14$ & $0.4 \pm 0.1$ \\
\hline
\end{tabular}

Table 2: Kinetic parameters of PTEN phosphatase activity measured with various substrates. Please refer to methods section for experimental details.

\begin{tabular}{|c|c|c|c|c|c|c|}
\hline & $\begin{array}{c}\text { PTP1B } \\
\text { bpVpic }\end{array}$ & $\begin{array}{c}\text { PTP1B } \\
\text { VO- } \\
\text { OHpic }\end{array}$ & $\begin{array}{c}\text { PTEN } \\
\text { bpVic }\end{array}$ & $\begin{array}{c}\text { PTEN } \\
\text { VO- } \\
\text { OHpic }\end{array}$ & $\begin{array}{c}\text { SopB } \\
\text { bpVpic }\end{array}$ & $\begin{array}{c}\text { SopB } \\
\text { VO- } \\
\text { OHpic }\end{array}$ \\
\hline HEPES & $37.5 \pm 1.6$ & $\begin{array}{c}790.3 \pm \\
41.8\end{array}$ & $29.3 \pm 3.1$ & $39.6 \pm$ & $42.3 \pm 6.2$ & $\begin{array}{c}513.6 \\
\pm 3.2\end{array}$ \\
\hline HEPES/EDTA & $60.5 \pm 2.2$ & $>20000$ & $36.3 \pm 4.3$ & $>20000$ & $50.3 \pm 5.3$ & $>20000$ \\
\hline
\end{tabular}

Table 3. IC50 values (nM) of PTEN, PTP1B and SopB inhibition by vanadium inhibitors bpVpic and VO-OHpic. Assays were performed using OMFP as substrate (see methods). The values shown are the mean \pm standard deviation of three independent experiments.

\section{Figures:}

Figure 1: 

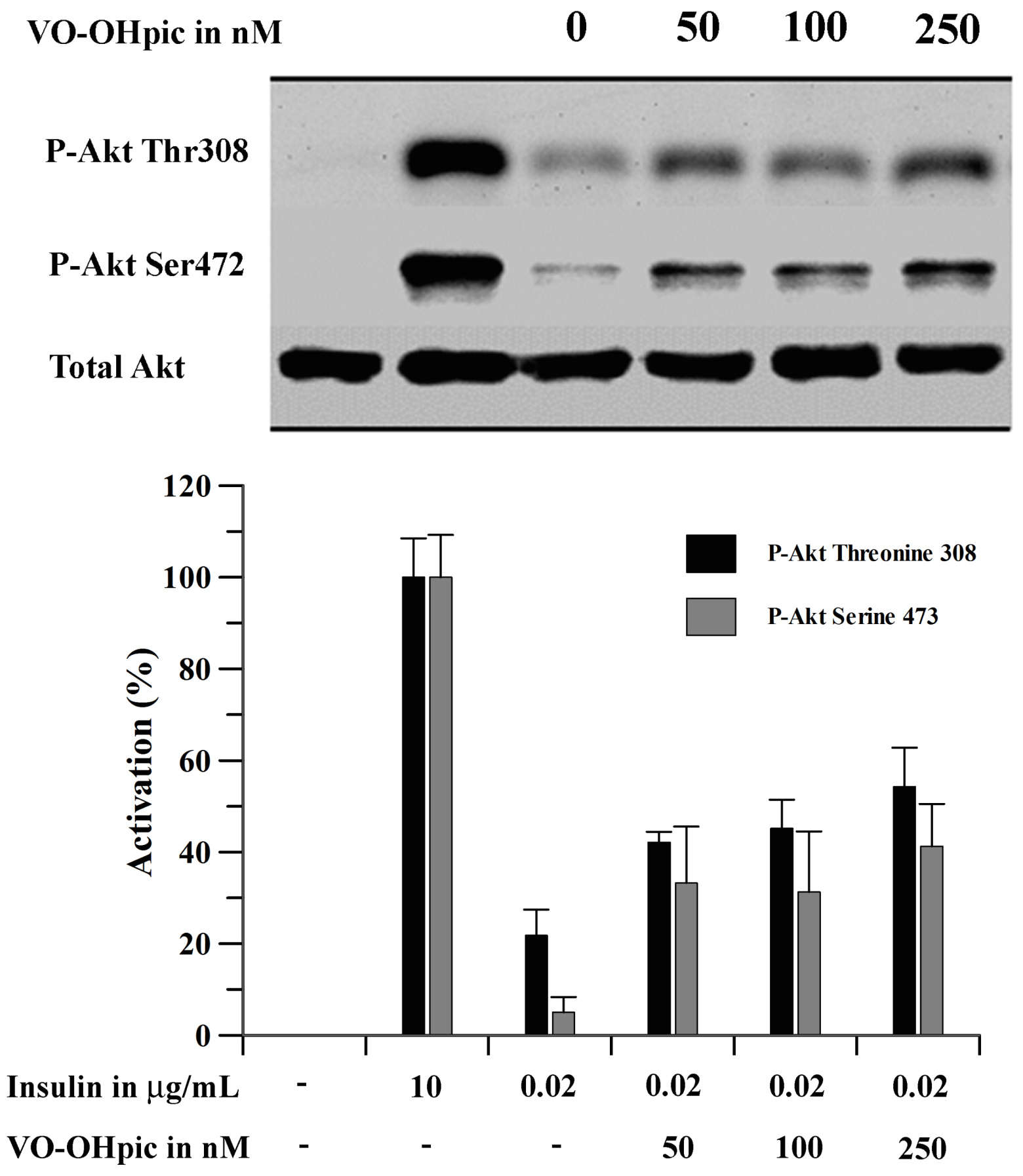

Figure 2: 


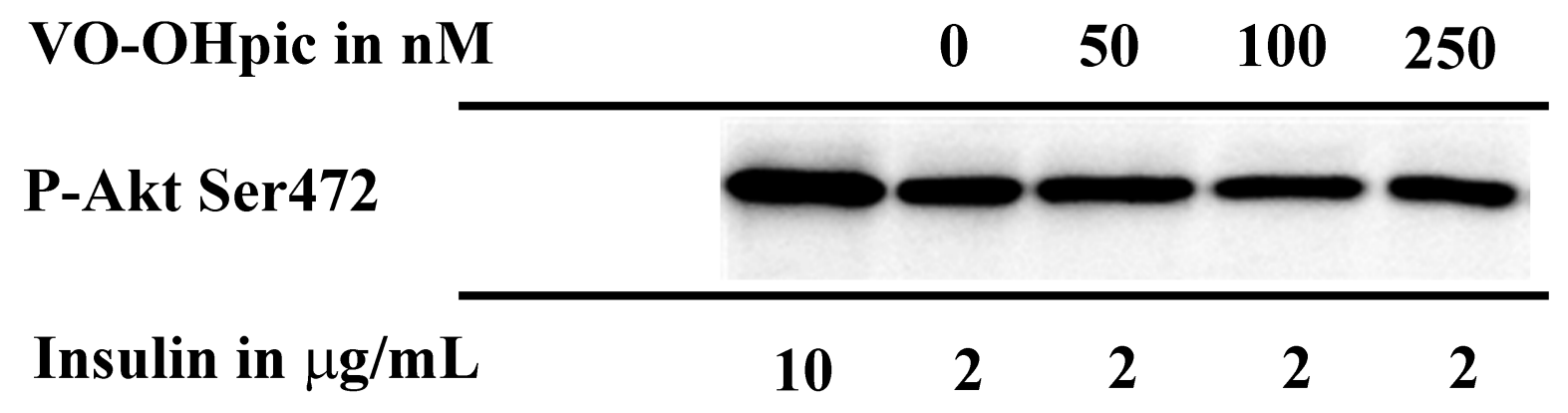

Figure 3:

\begin{tabular}{ccccc}
0 & 25 & 50 & 100 & 250 \\
\hline \multicolumn{4}{c}{ VO-OHpic in $\mathrm{nM}$}
\end{tabular}

